\title{
Approaching healthcare differently: engineering a brighter future for a public healthcare system
}

Welcome to the October edition of FHJ of 2018. Since I last wrote we have seen a change in leadership, both at the RCP and in the cabinet. Our new secretary of state is clearly a man with a passion for digital technology and now has the unenviable challenge of driving sustainable, innovative change in the NHS. Compared to his predecessor he has the fillip of an extra $£ 20$ billion as part of the funding settlement for the NHS's 70th birthday but he, and we, understand that money alone will not address the woes of the system in which we work. Most practitioners recognise that many of the models of care we are used to delivering need to modernise and we need to continuously look to fresh and innovative approaches to try and tackle system change throughout the NHS; this is clearly a huge challenge and one we have, to date, not really delivered a successful track record on.

The Future Hospital Commission was a true highlight produced in Jeremy Hunt's era, and one the RCP is rightly proud of. This journal grew out of that project and was designed to continue the conversation, across the whole of healthcare, to ensure that the vision of the work and the challenges it posed did not stop with the publication of the report. The editorial board of $F H$ J have, over the subsequent years, tried to cover many of the domains that are encompassed in a complex healthcare system and we are once again presenting a series of focused articles, this time on systems engineering and a systems approach to healthcare. This is the first of two issues that will explore this area in detail.

The articles in this edition of $\mathrm{FH}$ ] present an outline of how systems engineering principles may allow us to look at complex, multifaceted systems, such as the NHS, from a different perspective. ${ }^{1}$ It contains a challenge to us to properly assess proposed systems alterations comprehensively, from both a clinical and a cost-effectiveness viewpoint, ${ }^{2}$ and several articles convey how these approaches have reaped benefits in the USA, ${ }^{3} \mathrm{UK}^{4,5}$ and developing countries ${ }^{6}$. This edition of the journal also continues to address the issues around sustainability, highlighting the changes and challenges to our workforce, ${ }^{7}$ as well as the financial, professional, societal and environmental ${ }^{8}$ issues that we need to always continue to consider if we wish to maximise the likelihood of a sustainable system with the limited resources at our disposal.

Overall the focus of this edition of $\mathrm{FH}$ ] is on sustainable and effective systems redesign, with salient lessons presented that have been learnt from both successful and less successful endeavours; examples from the shop floor and among junior staff and patients, ${ }^{9}$ through to the effective use of data at a national level ${ }^{10}$ to understand the wider health economy and the challenges we face in using this ever-increasing data resource effectively.

All-in-all this is another packed edition of FHJ. I hope you find it stimulating and educational and maybe even find that it equips and empowers you to start tackling those complex issues that we endure each and everyday in delivering care to our patients.

\section{References}

1 Clarkson J, Dean J, Ward J, Komashie A, Bashford T. A systems approach to healthcare: from thinking to practice. Future Healthcare Journal 2018;5:151-5.

2 Young T, Morton A, Soorapanth S. Systems, design and value-formoney in the NHS: mission impossible? Future Healthcare Journal 2018;5:156-9.

3 Das P, Benneyan J, Powers L et al. Engineering safer care coordination from hospital to home: lessons from the USA. Future Healthcare Journal 2018;5:164-70.

4 Dodds S. Systems engineering in healthcare - A personal UK perspective. Future Healthcare Journal 2018;5:160-3.

5 Elameer M, Price C, Flynn D, Rodgers H. The impact of acute stroke service centralisation: a time series evaluation. Future Healthcare Journal 2018;5:181-7.

6 Bashford T, Myint PPN, Win S et al. A systems approach to trauma care in Myanmar: from health partnership to academic collaboration. Future Healthcare Journal 2018:5:171-5.

7 Smith F, Lambert TW, Goldacre MJ. The characteristics and views of early retirees compared with doctors still in work: views of the UK medical graduates of 1983 surveyed in 2016. Future Healthcare Journal 2018;5:192-7.

8 Runcie H. Sort your waste! An audit on the use of clinical waste bins and its implications. Future Healthcare Journal 2018;5:203-6.

9 Zaman Q, Yogamoorthy S, Zaman M, Fouda RMFR. Patients' perspective of physician associates in an acute medical unit within an English district general teaching hospital - a pilot survey study. Future Healthcare Journal 2018;5:213-7.

10 Aston SJ, Reade S, Petersen B et al. Extraordinary virtual multidisciplinary team meetings - a novel forum for the coordinated care of patients with complex conditions within a secondary care setting. Future Healthcare Journal 2018:5:2018-23.

Wing Commander Ed Nicol Editor-in-chief

Members of the editorial board
Wing Commander Edward Nicol
Editor-in-chief
Professor Tom Downes
Deputy editor-in-chief
Editorial board
Dr Na'eem Ahmed
Debra Armstrong

Dr Mohsin Choudry Dr John Dean Professor Paul Jenkins Dr Robert Klaber Dr David Morgan-Jones Dr Victoria Simpkin Dr Joanna Szram Dr Emma Vaux
Dr Louella Vaughan Ms Sheena Visram Dr Katharine Warburton Dr Stephen Webb Miss Jenny Isherwood Dr Frank Joseph Dr Mark Temple 